\title{
Determinants of ectopic pregnancy among pregnant women attending referral hospitals in southwestern part of Oromia regional state, Southwest Ethiopia: a multi- center case control study
}

\author{
Urge Gerema $^{1 *}$ (D), Tilahun Alemayehu', Getachew Chane ${ }^{1}$, Diliab Desta ${ }^{1}$ and Amenu Diriba ${ }^{2}$
}

\begin{abstract}
Background: Ectopic pregnancy is an abnormal condition in which implantation of the blastocyst occurs outside the endometrium of the uterus. It is gynecological important, particularly in the developing world, because of associated with enormous rate of high morbidity, during the first trimester of pregnancy. A better understanding of its risk factors can help to prevent its prevalence. However, the determinants of ectopic pregnancy are not well understood and few researches conducted in our country were based on secondary data covering small scale area. This study aimed to identify determinants of ectopic pregnancy among pregnant women attending referral hospitals in Southwestern part of Oromia regional state, Southwest Ethiopia.

Methods: Hospital-based case control study was employed from June 1 to September 30, 2019. The study was conducted in five referral hospitals in Southwestern part of Oromia regional state. Final sample size includes 59 cases and 118 controls. Data were entered by using Epidata version 3.1 and analyzed using SPSS version 23. Descriptive statistics were used to explore the data. All explanatory variables with $p$-value of $<0.25$ in bi-variable analysis, then entered into multivariable logistic regression. Associated factors were identified at $95 \%$ confidence interval $(p<0.05)$.

Results: Out of 177 (59 cases and 118 controls) participants, 174 (58 cases and 116 controls) were participating in the study. Prior two or more induced abortions [AOR $=3.95: 95 \% \mathrm{Cl}: 1.22-13.05]$, previous history of caesarean section $[A O R=3.4: 95 \% \mathrm{Cl}: 1.11-10.94]$, marital status (being single) $[\mathrm{AOR}=4.04: 95 \% \mathrm{Cl}: 1.23-13.21$, reporting prior recurrent sexual transmitted infection $[\mathrm{AOR}=2.25: 95 \% \mathrm{Cl}: 1.00-5.51]$, prior history of tubal surgery $[\mathrm{AOR}=3.32: 95 \% \mathrm{Cl}$ : 1.09-10.13], were more likely to have an ectopic pregnancy with their respective AOR with $95 \% \mathrm{Cl}$.

(Continued on next page)
\end{abstract}

\footnotetext{
* Correspondence: urgegerema@gmail.com

'Department of Biomedical sciences (Anatomy course unit), Jimma University, Jimma, Ethiopia

Full list of author information is available at the end of the article
}

(C) The Author(s). 2021 Open Access This article is licensed under a Creative Commons Attribution 4.0 International License, which permits use, sharing, adaptation, distribution and reproduction in any medium or format, as long as you give appropriate credit to the original author(s) and the source, provide a link to the Creative Commons licence, and indicate if changes were made. The images or other third party material in this article are included in the article's Creative Commons licence, unless indicated otherwise in a credit line to the material. If material is not included in the article's Creative Commons licence and your intended use is not permitted by statutory regulation or exceeds the permitted use, you will need to obtain permission directly from the copyright holder. To view a copy of this licence, visit http://creativecommons.org/licenses/by/4.0/ The Creative Commons Public Domain Dedication waiver (http://creativecommons.org/publicdomain/zero/1.0/) applies to the data made available in this article, unless otherwise stated in a credit line to the data. 
(Continued from previous page)

Conclusion: It was found that having a history of more than two induced abortions during previous pregnancies, marital status (single), recurrent sexual transmitted infection, prior history of tubal surgery and experiencing prior caesarean section were found to be determinants of ectopic pregnancy. Hospitals should give emphasis on prevention and early detection of risks of ectopic pregnancy and create awareness in order to reduce the burden of ectopic pregnancy.

Keywords: Ectopic pregnancy, Intrauterine pregnancy, Determinants, Southwest Ethiopia

\section{Background}

Ectopic pregnancy (EP) is an abnormal condition in which implantation of the blastocyst occurs outside the endometrium of the uterus. These abnormal sites of implantation in decreasing order of frequency include uterine tube (tubal pregnancy), abdominal cavity or on the mesentery (abdominal pregnancy), and in the ovaries (ovarian pregnancy) [1, 2]. Blastocysts that do not implant in the uterine wall are generally unable to develop normally because; the space is incapable for developing blastocyst. Ectopic pregnancy can cause ruptures of fallopian tube, cervix and abdomen on which they are implanted. Rupture of ectopic pregnancy result in severe bleeding, many organ damage, and maternal mortality [3-5]. It is obstetrical and gynecological important, especially in the developing world, because of the high maternal morbidity and mortality associated with it and the enormous threat to life particularly in the first trimester pregnancy [2]. It occurs in approximately $1-2 \%$ of pregnancies [4-7]. It is one of the top leading causes of maternal mortality in the first trimester and accounts for $10-15 \%$ of all maternal deaths [7]. Ectopic pregnancy is the leading cause of maternal morbidity and mortality worldwide [8].

In western world, the prevalence of ectopic pregnancy is approximately $2 \%$ in the general population, but as high as $20 \%$ in patients who have undergo tubal surgery, previous ectopic pregnancy [8]. The prevalence of ectopic pregnancy has an increasing trend during the last three decades throughout the world especially in developing countries where early diagnosis is low [3].

The causes of ectopic pregnancy are not well understood. However, multiple risk factors have been associated with ectopic pregnancy, although some patients may not have any risk factor to developed ectopic pregnancy. The main function of the oviduct is to provide the optimal environment for the transport and maturation of ovum and sperm for the establishment of pregnancy. Most data suggest that ectopic pregnancy causes from both abnormal zygote transport and change in the tubal environment, which enables abnormal implantation to occur [9-11].

In spite of different research done on the prevalence of ectopic pregnancy, however, the determinants of ectopic pregnancy are not well understood and few researches published in our country were based on secondary data covering small scale area and the study area has different characteristics cultural, religious, socio-demographic characteristics, sexual behavior, beliefs, contraception usage and practice from other area. The study was aimed to identify risk factors of ectopic pregnancy among pregnant women attending referral hospitals in Southwestern part of Oromia Regional state, Southwest Ethiopia.

This study result would worth to detect the potential risk factors of ectopic pregnancy in the study setup which would have further advantages to minimize morbidity and mortality of patients due to ectopic pregnancy. With regard to the preventable factors associated with ectopic pregnancy in the current population, this study is an important piece of work that could serve as an important source of information to design prevention strategies or to conduct further investigations.

\section{Methods}

\section{Study setting, design and population}

A multi-centered hospital-based case control study was conducted among pregnant women attending referral hospitals in Southwestern parts of Oromia regional state, Southwest Ethiopia from June 1 to September 30, 2019. All hospitals are teaching and referral hospital that gave general and specialized clinical services including ANC, family planning, delivery service \& treatment obstetric complications are some of the services provided in gynecologic and obstetric ward. These services have been delivered by senior midwives, gynecologists/obstetricians. All pregnant women attending gynecology and obstetrics department of JMC (Jimma Medical Center), WURH (Wollega University Referral Hospital), NRH (Nekemte Referral Hospital), AURH (Ambo Referral Hospital) and MKRH (Mettu Karl Referral Hospital) during the fourmonth study period were source population.

Study population: For cases all pregnant women who had been confirmed by ultrasound and HCG to have EP in the inpatient department of gynecology and obstetrics of each hospital were recruited. For controls: Controls were sampled pregnant women confirmed by ultrasound and HCG to have intra uterine pregnancy at the prenatal 
clinic in department of gynecology and obstetrics of each hospital.

\section{Eligibility criteria}

\section{Inclusion criteria for cases}

admitted women who had been confirmed by ultrasound and HCG to have EP in the inpatient department of gynecology and obstetrics of each hospital. For controls: Controls were sampled pregnant women confirmed by ultrasound and HCG to have intra uterine pregnancy at the prenatal clinic in department of gynecology and obstetrics of each hospital.

\section{Exclusion criteria for both cases and controls}

Women with serious medical conditions and couldn't give consent were excluded from the study.

\section{Case definition}

Case pregnant women diagnosed by hCG and ultrasound to have ectopic pregnancy confirmed by Obstetrician/gynecologist [12].

\section{Control}

Pregnant women diagnosed by hCG and ultrasound to have intrauterine pregnancy confirmed by Obstetrician/ gynecologist [12].

\section{Sample size and sampling procedure}

The required sample size was determined by using Epiinfo version 7 statistical software for unmatched casecontrol study design. Results from similar studies were used to approximate the sample size in different potential risk factors of ectopic pregnancy. In a study report from India prior tubal surgery was a significant risk factor for ectopic pregnancy [13]. A case control study in western Ethiopia at Nekemte hospital marital status was a significant risk factor for ectopic pregnancy [14]. Similarly, case control study done in Turkey Ankara previous history of ectopic pregnancy was a significant risk factor for ectopic pregnancy [15]. Using these reports as starting point, similar assumptions $\mathrm{P} 1$ : proportion among cases and p2: proportion of among controls AOR: Adjusted odds ratio at $95 \%(\mathbf{Z \alpha} / \mathbf{2}=1.96)$ level of confidence, Power of study $=80 \%$ Ratio of cases to controls = 1:2 (Table 1).
From the above three significant risk factors of ectopic pregnancy, previous history of ectopic pregnancy gives the large sample size which gives total of 177 study participants (59 cases and 118 controls). In the selected five referral hospitals the number of pregnant. Women registered during the $2018 \mathrm{G}$. C HMIS report over 4 months at JMC, WURH, NRH, AURH and MKRH were 1707, 1085, 679, 1489 and 1219 respectively.

The calculated sample size was proportionally allocated based on the estimated number of pregnant women in selected referral hospitals. Therefore (16 cases and 32 controls) from JMC, (10 cases and 20 controls) from WURH, (7 cases and 14 controls) from NRH, (14 cases and 28 controls) from AURH and (12 cases and 28 controls) from MKRH. Then, the study participant was selected using consecutive sampling technique.

\section{Data collection tools and procedures}

The data were collected by face to face interview using semi structured questionnaire addressing sociodemographic and obstetric, gynecologic, behavioral, surgical history and contraceptive characteristics of study participants which was developed after reviewing different literatures. Fifteen trained data collectors and five supervisors were involved in the process.

\section{Data quality control}

The urine sample collection was done through standardized, and sterile technique by professional laboratory technologists, ultrasound was calibrated before the procedure. The diagnosis of pregnancy was confirmed by Trans abdominal ultrasonography combined to the hCG.

Data quality was ensured during data collection, coding, entry and analysis. During data collection adequate training and follow up was provided to data collectors and supervisors. Incomplete checklists were returned back to the data collector for completion. Codes were given to the questionnaires and during the data collection so that any identified errors was traced back using the codes.

\section{Data processing and analysis}

Collected data were rechecked for completeness, consistency and coded before data entry. Data were entered using Epi data version 3.1 and data from five hospitals were merged together, and then exported to the

Table 1 Epi Info sample size calculation

\begin{tabular}{|c|c|c|c|c|c|c|}
\hline \multirow[t]{2}{*}{ Exposure variables } & \multirow{2}{*}{$\begin{array}{l}\text { Proportion } \\
\text { ion among } \\
\text { cases }\end{array}$} & \multirow{2}{*}{$\begin{array}{l}\text { Proportion } \\
\text { on among } \\
\text { controls }\end{array}$} & \multirow[t]{2}{*}{ AOR } & \multicolumn{2}{|c|}{ Sample size } & \multirow{2}{*}{$\begin{array}{l}\text { Final Sample } \\
\text { Adding } 10 \% \\
\text { nonresponse }\end{array}$} \\
\hline & & & & Cases & Controls & \\
\hline Pervious History of ectopic pregnancy & 9.7 & 1.3 & 13.1 & 53 & 106 & 177 \\
\hline Single marital status & 25 & 3 & 10.8 & 32 & 64 & 105 \\
\hline Pervious tubal surgery & 44 & 3 & 14 & 25 & 50 & 84 \\
\hline
\end{tabular}


Statistical Package for Social Science (SPSS) version 23 for analysis. Descriptive analysis was conducted to explore the data and present some variables. Bi-variable binary logistic regression analysis was executed to select candidate variable for multivariable binary logistic regression to identify the predictors. Variables with $p$-value of less than 0.25 were selected for multivariable logistic regression. Odds ratio (OR) and 95\% confidence intervals $(\mathrm{CI})$ were used to describe the association between ectopic pregnancy and potential risk factors. Variables with a $p$-value $<0.05$ in multi-variable analysis was considered as a significant risk factor for ectopic pregnancy.

\section{Results}

\section{Socio-demographic characteristics}

In this prospective case control study conducted over four-months from June 1 to September 30, 2019 at five government referral hospitals found in Southwestern part Oromia, Ethiopia. A total of 174 pregnant women; 58 Cases (EP) and 116 Controls (IUP) were participated. The mean age was $26( \pm 5.54), 26$ ( \pm 4.87 years for cases and controls respectively.

Almost two-third (63.8\%) of cases and 79 (68.1\%) of controls were aged between 21 and 30 years. Eighteen (31\%) cases and $39(33 \%)$ of controls were orthodox in religion and $37(63.8 \%)$ of cases and $79(68.1 \%)$ of controls were Oromo by their ethnicity and $37(63.8 \%)$ cases and $95(81.9 \%)$ of controls were married. About 18 (31\%) cases and $46(39.7 \%)$ controls were house wives in occupation (Table 2).

\section{Behavioral characteristics}

Only one case (1.7\%) and two controls (1.7\%) had occasional history of cigarette smoking and only 18(31.1\%) cases and 34(29.3\%) controls history of occasionally alcohol consumption before current pregnancy (Table 3).

\section{Obstetrics and surgical history of participants}

As indicated in the Table 4, three of the cases (5.1\%) and another three women in the control group (2.6\%) had prior history of ectopic pregnancy. Seven women in each of the study groups (12.0\% of the cases and $6.0 \%$ of the controls) had more than two prior history of spontaneous abortion. Similarly, 8 (13.8\%) cases and 6 (5.1\%) controls reported two or more prior history of induced abortions. This study shows that $10(17.2 \%)$ of cases and $6(5.1 \%)$ controls had caesarean section before current pregnancy. Eleven (18.1\%) of cases and 6(5.2\%) controls had at least one tubal pregnancy before current pregnancy for any reason (Table 4).

\section{Gynecologic and contraceptive history of participants} About 36.2\% (21/58) of the cases and 16 (13.7\%) controls had prior history of a recurrent.
STD/STI. Majority 42 (72.4\%) of the cases and 92 (79.3\%) controls had prior history of oral contraceptive use. Only $6(10.3 \%)$ cases and 15(12.9\%) controls had history of IUCD use.

Twenty (34.4\%) cases and 18 (10.8\%) controls reported practice of emergency contraceptives pills use before the current conception (Table 5).

\section{Factors associated with ectopic pregnancy}

Findings from bi-variable logistic regression analysis showed that marital status, prior history of induced abortions, prior history of spontaneous abortions, prior history of tubal surgery, prior history of caesarean section, prior history of tubal ligation and history of recurrent STD/STI had associated with ectopic pregnancy with p-value of $<0.25$, However, in.

multivariable regression analysis, history of two or more induced abortions $[\mathrm{AOR}=3.42: 95 \% \mathrm{CI}$ : $1.06-$ 11.05], prior history of caesarean section $[\mathrm{AOR}=3.48$ : 95\% CI: 1.14-10.13], prior history of tubal surgery [AOR $=3.32: 95 \% \mathrm{CI}:$ 1.09-10.13], marital status (being single) $[\mathrm{AOR}=3.23: 95 \% \mathrm{CI}: 1.02-10.22]$, prior recurrent STD/STI $[\mathrm{AOR}=3.08: 95 \% \mathrm{CI}: 1.38-6.88\}$ remained statistically significant risk factor for ectopic pregnancy (Table 6).

\section{Discussion}

This was a multi-centered hospital based case control study which, was aimed to identify determinants of ectopic pregnancy among pregnant women attending referral hospitals in Southwestern parts of Oromia regional state, Southwest Ethiopia. Being single were independent predictors of ectopic pregnancy. A similar association was reported in studies done in west Ethiopia Nekemte and Uganda $[14,16]$. The association between being single and ectopic pregnancy infection could be explained by the fact that single women engaged in multiple sexual partners following successive infection, ascending infection result in adhesions, impede the morula retention of movement causing implantation in the tube and other site.

Having more than two times history of induced abortion found was statistically significant relation with ectopic pregnancy. This finding was supported by a study done in; India, Tigray, Ethiopia and Nigeria [17-19]. The association might be explained by most abortions are illegal different countries and usually performed in poor aseptic conditions. Thus, increasing post-abortion sepsis risk and subsequent PID.

Women who had a prior history of recurrent STI were significantly associated with ectopic pregnancy. This finding was similar to studies done in Ethiopia, Ghana [20]. The association between STD/STI and ectopic pregnancy might be successive infection, ascending 
Table 2 Socio-demographic characteristics of participants at referral hospitals in Southwestern part of Oromia region, Southwest Ethiopia ( $n=174)$, September 2019

\begin{tabular}{|c|c|c|c|}
\hline Characteristics & Category & Cases $(N=58) \mathrm{N}(\%)$ & Controls $(N=116) \mathrm{N}(\%)$ \\
\hline \multirow[t]{3}{*}{ Age in year } & $<=20$ & $10(17.2 \%)$ & $14(12.1 \%)$ \\
\hline & $21-30$ & $37(63.8 \%)$ & 79 (68.1\%) \\
\hline & $>=30$ & $11(18.9 \%)$ & $23(19.8)$ \\
\hline \multirow[t]{2}{*}{ Residence } & Urban & $27(46.6 \%)$ & $54(46.6 \%)$ \\
\hline & Rural & $31(53.4 \%)$ & $62(53.4 \%)$ \\
\hline \multirow[t]{4}{*}{ Religion } & Orthodox & $18(31.0 \%)$ & $39(33.6 \%)$ \\
\hline & Muslim & $15(25.8 \%)$ & $29(25.0 \%)$ \\
\hline & Protestant & $20(34.4 \%)$ & $33(28.4 \%)$ \\
\hline & Others & $5(8.6 \%)$ & $15(12.9 \%)$ \\
\hline \multirow[t]{4}{*}{ Ethnicity } & Oromo & $37(63.8 \%)$ & 79 (68.1\%) \\
\hline & Amhara & $11(18.9 \%)$ & $24(20.7 \%)$ \\
\hline & Dawuro & $5(8.6 \%)$ & $7(6.0 \%)$ \\
\hline & Gurage & $5(8.6 \%)$ & $6(5.2 \%)$ \\
\hline Marital status of & Single & $9(15.5 \%)$ & $7(6.0 \%)$ \\
\hline \multirow[t]{2}{*}{ Respondent } & Married & 37 (63.8\%) & $95(81.9 \%)$ \\
\hline & Others & $12(13.7 \%)$ & $14(12.08 \%)$ \\
\hline \multirow[t]{5}{*}{ Educational status } & Can't read \&write & $6(10.3 \%)$ & $5(4.3 \%)$ \\
\hline & Read \&write only & $10(17.2 \%)$ & $17(14.7 \%)$ \\
\hline & Grade 1-8 & $18(31.0 \%)$ & $48(41.4 \%)$ \\
\hline & Grade 9-12 & $15(25.8 \%)$ & $32(27.3 \%)$ \\
\hline & Diploma and above & $9(15.5 \%)$ & $14(12.1 \%)$ \\
\hline Occupational & Housewife & $15(25.8 \%)$ & $38(32.7 \%)$ \\
\hline status of & Farmer & $13(22.1 \%)$ & 22 (18.9\%) \\
\hline \multirow[t]{4}{*}{ Respondent } & Gov't employee & $13(22.4 \%)$ & $25(21.6 \%)$ \\
\hline & NGO & $4(6.8 \%)$ & $10(8.6 \%)$ \\
\hline & Merchant & $6(10.3 \%)$ & $10(8.6 \%)$ \\
\hline & Laborer & 7 (12.1\%) & 11 (9.5\%) \\
\hline \multirow[t]{5}{*}{ Income in ETB } & $<1000$ & $14(24.1 \%)$ & $23(20.6 \%)$ \\
\hline & $1001-2000$ & 10 (20.7\%) & $23(19.8 \%)$ \\
\hline & 2001-3000 & 15 (25.7\%) & $26(22.4 \%)$ \\
\hline & $3001-4000$ & $12(10.3 \%)$ & $25(20.6 \%)$ \\
\hline & $>4001$ & 7 (12.1\%) & 19 (16.4\%) \\
\hline
\end{tabular}

Table 3 Behavioral characteristics of participants in Southwestern referral hospitals in Oromia regional state, Southwest Ethiopia $(n=$ 174), September 2019

\begin{tabular}{llll}
\hline Habits & Category & Cases $(\boldsymbol{N}=\mathbf{5 8}), \mathbf{N}(\%)$ & Controls $(\mathbf{N}=\mathbf{1 1 6}, \mathbf{N}(\mathbf{\%})$ \\
\hline History of cigarette & Non smoker & $57(98.2 \%)$ & $114(98.3 \%)$ \\
& Occasional smoker & $1(1.7 \%)$ & $2(1.7 \%)$ \\
History of alcohol d & Non drinker & $40(68.9 \%)$ & $82(70.7 \%)$ \\
& Occasional drinker & $18(31.1 \%)$ & $34(29.3 \%)$ \\
\hline
\end{tabular}


Table 4 Obstetrics and surgical history of participants in Southwestern referral. Hospitals in Oromia regional state, Southwest Ethiopia $(n=174)$, September 2019

\begin{tabular}{|c|c|c|c|c|}
\hline \multirow{2}{*}{$\begin{array}{l}\text { Characteristics }(N=174) \text {. } \\
\text { Prior history of ectopic }\end{array}$} & \multirow{2}{*}{$\begin{array}{l}\text { Category } \\
\text { Yes }\end{array}$} & \multicolumn{2}{|c|}{ Cases $(N=58) \mathrm{N}(\%)$} & \multirow{2}{*}{$\begin{array}{l}\text { Controls }(\boldsymbol{N}=\mathbf{1 1 6 , \mathrm { N }}(\%) \\
3(2.6 \%)\end{array}$} \\
\hline & & 3 & $(5.1 \%)$ & \\
\hline Pregnancy & No & $55(94.8 \%)$ & & $113(97.4 \%)$ \\
\hline Prior history of spontaneous & 0 & $42(72.4 \%)$ & & 97 (83.6\%) \\
\hline \multirow[t]{2}{*}{ Abortion } & 1 & 9 & $(15.5 \%)$ & $12(10.3 \%)$ \\
\hline & $>=2$ & 7 & (12.0\%) & $7(6.0 \%)$ \\
\hline Prior history of Induced & 0 & 40 (68.9\%) & & $96(82.8 \%)$ \\
\hline \multirow[t]{2}{*}{ Abortion } & 1 & $10(17.2 \%)$ & & $14(12.1 \%)$ \\
\hline & $>=2$ & 8 & $(13.8 \%)$ & $6(5.1 \%)$ \\
\hline Prior history of caesarean & Yes & $10(17.2 \%)$ & & $6(5.1 \%)$ \\
\hline Section & No & $48(82.7 \%)$ & & $110(94.8 \%)$ \\
\hline Prior history of & Yes & 1 & $(1.7 \%)$ & $4(3.4 \%)$ \\
\hline Appendectomy & No & $57(98.3 \%)$ & & $112(96.6 \%)$ \\
\hline \multirow[t]{2}{*}{ Prior history of tubal surgery } & Yes & $11(18.9 \%)$ & & $6(5.2 \%)$ \\
\hline & No & $47(81.1 \%)$ & & $110(94.8 \%)$ \\
\hline \multirow[t]{2}{*}{ Prior history of tubal ligation } & Yes & 5 & $(8.6 \%)$ & $5(4.3 \%)$ \\
\hline & No & $53(91.4 \%)$ & & $111(95.7 \%)$ \\
\hline \multirow[t]{3}{*}{ Parity } & 0 & $19(32.7 \%)$ & & $43(37.1 \%)$ \\
\hline & 1 & 22 (37.9\%) & & 48 (41.3\%) \\
\hline & $>=2$ & 17 (29.3\%) & & 25 (21.6\%) \\
\hline
\end{tabular}

infection result in salphingitis leads to tubal dysfunction, decrease cilia density; ciliary beat this result in retention of morula in the fallopian tube and implantation of blastocyst in the fallopian tube and other site.

Women having at least one caesarean section for previous pregnancy were independently associated with ectopic pregnancy. This study supported by a study done in Turkey [15]. The underlying mechanism of association between previous caesarean section and occurrence of ectopic pregnancy is might be due to increased pelvic infection and adhesion after caesarean section which disturbs the micro environment of the tube and implantation of blastocyst in the tube.

Table 5 Gynecologic and contraceptive history of participants in Southwestern referral hospitals in Oromia regional state, Southwest Ethiopia $(n=174)$, September 2019

\begin{tabular}{|c|c|c|c|c|}
\hline \multirow[t]{2}{*}{ Characteristics } & \multirow[t]{2}{*}{ Category } & \multirow{2}{*}{$\begin{array}{l}\text { Cases }(N=58), \\
\mathrm{N}(\%)\end{array}$} & \multicolumn{2}{|c|}{ Controls $(N=116)$} \\
\hline & & & $\mathrm{N}(\%)$ & \\
\hline \multirow[t]{2}{*}{ Prior recurrent STD/STI } & Yes & $21(36.2 \%)$ & 16 & $(13.7 \%)$ \\
\hline & No & $37(63.7 \%)$ & $100(86.2 \%)$ & \\
\hline Prior history condom & Yes & $16(27.5 \%)$ & 28 & $(33.6 \%)$ \\
\hline Usage & No & $42(72.4 \%)$ & 88 & $(75.8 \%)$ \\
\hline Prior history of IUCD & Yes & $6(10.3 \%)$ & 15 & $(12.9 \%)$ \\
\hline Usage & No & $52(89.7 \%)$ & $101(87.1 \%)$ & \\
\hline \multirow[t]{2}{*}{ Prior history of OCP } & Yes & $42(72.4 \%)$ & 92 & $(79.3 \%)$ \\
\hline & No & $16(27.6 \%)$ & 24 & $(20.7)$ \\
\hline \multirow[t]{2}{*}{ Prior history of Injectable Yes } & & $25(43.1 \%)$ & 50 & $(43.1 \%)$ \\
\hline & No & $33(56.9 \%)$ & 66 & $(56.9 \%$ \\
\hline Prior history of implant & Yes & $15(25.9 \%)$ & 34 & $(29.3 \%)$ \\
\hline Use & No & $43(74.1 \%)$ & 82 & $(70.7 \%)$ \\
\hline
\end{tabular}


Table 6 Bivariate and multivariate logistic regression

\begin{tabular}{|c|c|c|c|c|c|}
\hline \multirow[t]{2}{*}{ Variables } & \multirow[t]{2}{*}{ Category } & \multicolumn{2}{|c|}{ Status of ectopic pregnancy } & \multirow{2}{*}{$\begin{array}{l}\text { COR } \\
(95 \% \text { C.I) }\end{array}$} & \multirow{2}{*}{$\begin{array}{l}\text { AOR }(95 \% \text { C.I) } \\
P \text { value }\end{array}$} \\
\hline & & Cases $(N=58) \mathrm{N}(\%)$ & Controls $(N=116) \mathrm{N}(\%)$ & & \\
\hline \multirow[t]{3}{*}{ Marital status of respondent } & Single & $9(15.5 \%)$ & $7(6.0 \%)$ & $3.31[1.14-9.51]$ & $\mathbf{3 . 2 2}[1.02: 10.22] \mathbf{0 . 0 4}{ }^{*}$ \\
\hline & Married & $37(63.8 \%)$ & 95(81.9\%) & 1 & \\
\hline & Others & $12(13.7 \%)$ & $14(12.08 \%)$ & $2.2[0.93-5.1]$ & $2.0[0.75-5.36] 0.16$ \\
\hline \multirow[t]{3}{*}{ Prior history of spontaneous abortions } & 0 & $42(72.4 \%)$ & $97(83.6 \%)$ & 1 & \\
\hline & 1 & $9(15.5 \%)$ & $12(10.3 \%)$ & $1.73[0.67-4.42]$ & $1.48[0.50-4.37] 0.43$ \\
\hline & $>=2$ & $7(12.0 \%)$ & 6(12.0) & $2.3[0.76-6.97]$ & $1.68[0.45-0.62] 0.48$ \\
\hline \multirow[t]{3}{*}{ Prior history of induced abortion } & 0 & $40(68.9 \%)$ & $96(82.8 \%)$ & 1 & \\
\hline & 1 & $10(17.2 \%)$ & $14(12.1 \%)$ & $1.71[0.71-4.18]$ & $1.72[0.66-4.51] 0.26$ \\
\hline & $>=2$ & $8(13.8 \%)$ & $6(5.1 \%)$ & $3.2[1.04-9.81]$ & $\mathbf{3 . 4 2}[1.06-11.1] \mathbf{0 . 0 4 *}$ \\
\hline \multirow[t]{2}{*}{ Previous history of caesarean section } & Yes & $10(17.2 \%)$ & $6(5.1 \%)$ & $3.82[1.49-12.2]$ & $3.48[1.14-10.6] 0.028^{*}$ \\
\hline & No & $48(82.7 \%)$ & $110(94.8 \%)$ & 1 & \\
\hline \multirow[t]{2}{*}{ Prior history of tubal surgery } & Yes & $11(18.9 \%)$ & $6(5.2 \%)$ & $4.3[1.49-12.28]$ & $\mathbf{3 . 3 2}[1.1-10.13] \mathbf{0 . 0 3 5}$ * \\
\hline & No & 47(81.1\%) & $110(94.8 \%)$ & 1 & \\
\hline \multirow[t]{2}{*}{ Tubal ligation } & Yes & $5(8.6 \%)$ & $5(4.3 \%)$ & $2.64[0.64-10.3]$ & $1.32[0.26-6.64) 0.73$ \\
\hline & No & 53(91.4\%) & $111(95.7 \%)$ & 1 & \\
\hline \multirow[t]{2}{*}{ Prior STD/STI } & Yes & $21(36.2 \%)$ & $16(13.7 \%)$ & $3.55[1.67-7.52]$ & $\mathbf{2 . 3 5}[1.0-5.51] \mathbf{0 . 0 4 9 ^ { * }}$ \\
\hline & No & $37(63.7 \%)$ & $100(86.2 \%)$ & 1 & \\
\hline
\end{tabular}

*value statistically significant, $A O R$ adjusted odds ratio, COR crude odds ratio, $C l$ confidence interval, 1-reference

In the present study, women who had a prior history of tubal surgery were statistically significant with ectopic pregnancy. This study is supported by study done in Egypt and Uganda [16]. The association might be explained by the scar on the Fallopian tube may interfere with the ovum transport and implantation of blastocyst in the Fallopian tube.

I did not find any association between appendectomy, prior use of IUCD, cigarette smoking, alcohol drinking and previous history of ectopic pregnancy, previous tubal surgery with present study, probably the number of the studied participants was too small.

\section{Limitations and strengths of the study}

Due to a small number of cases obtained from each hospital, this study did not compare among the five hospitals with regard to risk factors of EP and study assesses history of exposure retrospectively, it may be prone to recall and selection bias by nature during the data collection time. The study has some strengths this study used the primary data from the participants. Further, the study was multi-centered hospital based case control.

\section{Conclusions}

It was found that having a history of more than two induced abortions during previous pregnancy, marital status (single), experiencing at least one caesarean section for previous pregnancies, prior history of STD/STI and using emergency contraceptive pills during the cycle of conception were found important determinants of ectopic pregnancy in the study population. Women with history of previous induced abortion and previous caesarean section STD/STI should be followed up carefully, even in the absence of symptoms should always be counseled about the possibility of ectopic pregnancy and the associated risks.

\section{Supplementary Information}

The online version contains supplementary material available at https://doi. org/10.1186/s12884-021-03618-7.

Additional file 1.

\section{Abbreviations}

AOR: Adjusted odd ratio; AURH: Ambo University Referral Hospital; COR: Crude odd ratio; EP: Ectopic pregnancy; HCG: Humanchorionic gonadotropin; HMIS: Health Management Information system; IUP: Intra uterine pregnancy; JMC: Jimma Medical Center; MKRH: Mettu Karl Referral Hospital; NRH: Nekemte Referral Hospital; STD: Sexual transmitted diseases; STI: Sexual transmitted infection

\section{Acknowledgments}

We would like to thank Jimma University for allowing me to conduct this study. Also we would like to thanks the study participants, data collectors and supervisors.

\section{Authors' contributions}

UG involved in conceiving the idea, study design, data analysis and interpretation, writing the manuscript and managing the overall progress of the study. TA, G CH, DD and AD involved in study design, data analysis and in revising the manuscript. The final manuscript was read and approved by all the authors. 


\section{Funding}

There is no funding for this study.

\section{Availability of data and materials}

The datasets used and/or analyzed during the current study are available from the corresponding author on reasonable request.

\section{Ethics approval and consent to participate}

Ethical approval or clearance letter RPSCMF/0132/19 was obtained from institutional review board (IRB) of Institute of Health, Jimma University. Permission letter was written to respective hospitals administration office, and the study was commencing after receiving formal permission from them. The Institutional review board approved the verbal consent. Due to low literacy level informed verbal consent was obtained from each respondent after they had been taken through the respondent information sheet. Data collectors maintained confidentiality through excluding names or any other personal identifiers from data collection sheets and reports.

\section{Consent for publication}

Not applicable.

\section{Competing interests}

The authors declare that they have no competing interests.

\section{Author details}

'Department of Biomedical sciences (Anatomy course unit), Jimma University, Jimma, Ethiopia. ${ }^{2}$ Department of gynecology and obstetrics, Wellega University, Wellega, Ethiopia.

Received: 3 January 2020 Accepted: 3 February 2021

Published online: 12 February 2021

\section{References}

1. Bhuria V, Nanda S, Chauhan M, Malhotra V. A retrospective analysis of ectopic pregnancy at a tertiary care Centre: one year study. Int J Reproduct Contracept Obstetr Gynecol. 2016;5:2224-7.

2. Gaym A. Maternal mortality studies in Ethiopia--magnitude, causes and trends. Ethiop Med J. 2009;47(2):95-108.

3. Yeasmin MS, Uddin MJ, Hasan E. A clinical study of ectopic pregnancies in a tertiary care hospital of Chittagong, Bangladesh. Chattagram Maa-O-Shishu Hosp Med Coll J. 2014;13(3):1-4.

4. Gharoro EP, Igbafe AA. Ectopic pregnancy revisited in Benin City, Nigeria: analysis of 152 cases. Acta Obstet Gynecol Scand. 2002;81(12):1139-43.

5. Basnet R, Pradhan N, Bharati L, Bhattarai N, Bb B, Sharma B. To determine the risk factors associated with ectopic pregnancy. Asian J Pharm Clin Res. 2015:8(2):93-7.

6. Porricelli JD, Boyd JH. Analytical Techniques for Predicting Grounded Ship Response. Engineering computer opt economics inc Annapolis md; 1983.

7. Dabota BY. Management and outcome of ectopic pregnancy in developing countries. Ectopic Pregnancy. 2011;109:10-8.

8. Panchal D, Vaishnav G, Solanki K. Study of management in patient with ectopic pregnancy. Infection. 2011;33:55

9. Shaw JL, Dey SK, Critchley HO, Horne AW. Current knowledge of the etiology of human tubal ectopic pregnancy. Hum Reprod Update. 2010; 16(4):432-44.

10. Jacob L, Kalder M, Kostev K. Risk factors for ectopic pregnancy in Germany: a retrospective study of 100,197 patients. GMS German Med Sci. 2017;15:334.

11. John CO, Alegbleye JO. Ectopic pregnancy experience in a tertiary health facility in South-South Nigeria. Nigerian Health J. 2016;16(1):2-5

12. Schoenwolf, G.C., Bleyl, S.B., Brauer, P.R., Francis-West, P.H. \& Philippa H. (2015). Larsen's human embryology (5th ed.). New York; Edinburgh: Churchill Livingstone.

13. Bhandari G, Yadav KK, Shah R. Ectopic pregnancy and its risk factors: a case control study in Nepalese women. J BP Koirala Inst Health Sci. 2018;1(2):30-4.

14. Kebede Y, Dessie G. Determinants of ectopic pregnancy among pregnant women who were managed in Nekemte referral hospital, Oromia Region, Ethiopia. J Preg Child Health. 2018;5(370):2.

15. Karaer A, Avsar FA, Batioglu S. Risk factors for ectopic pregnancy: a casecontrol study. Aust N Z J Obstet Gynaecol. 2006;46(6):521-7.
16. Dp M, Lugobe $H$, Ssemujju A. Factors associated with ectopic pregnancy at Mbarara University teaching Hospital in South Western Uganda. Reprod Med. 2018;2(4):2-7.

17. Kassebaum NJ, Barber RM, Bhutta ZA, Dandona L, Gething PW, Hay SI, Kinfu Y, Larson HJ, Liang X, Lim SS, Lopez AD. Global, regional, and national levels of maternal mortality, 1990-2015: a systematic analysis for the global burden of disease study 2015. Lancet. 2016;388(10053):1775-812.

18. Abebe D, Tukue D, Aregay A, Gebremariam L. Magnitude and associated factors with ectopic pregnancy treated in Adigrt hospital, Tigray region, Northern Ethiopia. Int J Res Pharm Sci. 2017;7(1):30-39.

19. Lawani OL, Anozie OB, Ezeonu PO. Ectopic pregnancy: a life-threatening gynecological emergency. Int J Women's Health. 2013;5:515.

20. Chow JM, Yonekura ML, Richwald GA, Greenland S, Sweet RL, Schachter J. The association between chlamydia trachomatis and ectopic pregnancy: a matched-pair, case-control study. JAMA. 1990;263(23):3164-7.

\section{Publisher's Note}

Springer Nature remains neutral with regard to jurisdictional claims in published maps and institutional affiliations.

\section{Ready to submit your research? Choose BMC and benefit from:}

- fast, convenient online submission

- thorough peer review by experienced researchers in your field

- rapid publication on acceptance

- support for research data, including large and complex data types

- gold Open Access which fosters wider collaboration and increased citations

- maximum visibility for your research: over $100 \mathrm{M}$ website views per year

At BMC, research is always in progress.

Learn more biomedcentral.com/submissions 